\title{
Editorial
}

\section{5 anos de publicações de uma revista plural}

É com orgulho e satisfação que nos dirigimos neste editorial aos psiquiatras brasileiros e profissionais ligados à saúde mental, nosso público leitor, para entregar mais um número e comemorar 25 anos de ininterruptas publicações da Revista de Psiquiatria do Rio Grande do Sul.

O quarto de século de publicações da Revista é um momento oportuno para comemorarmos as realizações e o crescimento da Revista e também para fazermos reflexões, revermos os acertos, os erros e as possibilidades de correções de rumos no cumprimento com nossa responsabilidade científica.

É dentro deste contexto que convidamos todos a fazerem uma reflexão sobre este quarto de século da Revista, em que constatamos um constante crescimento e consolidação cada vez maior de sua identidade plural. A pluralidade de idéias e vértices científicos é, em nosso entender, o que de melhor podemos oferecer aos psiquiatras e profissionais da área de saúde mental sobre os mais diversos avanços científicos nas distintas instâncias do complexo comportamento e funcionamento da mente humana. Nossa Revista tem por objetivo publicar artigos originais, revisões, estudos de casos, comunicações breves, resenhas e cartas nas áreas de psiquiatria clínica, psicanálise, psicoterapias, neurociências, epidemiologia, saúde pública, pesquisas, enfim, as mais diversas correntes de interesse da comunidade científica. Almejamos contribuir para a constante atualização do psiquiatra contemporâneo.

A excelência de uma publicação respeitável, entretanto, é feita com o envolvimento amplo de quem produz conhecimento científico. É nesse sentido que a Revista pode se orgulhar de contar com uma lista extensa de incansáveis colaboradores desde o seu nascimento - e seria impossível aqui nomeá-los, sob pena de cometer injustiça ao esquecer de citar algum nome. Num levantamento desses 25 anos, realizado pela nossa secretária, Sandra Schmaedecke, a quem muito temos a agradecer por sua dedicação à Revista, constatamos alguns interessantes dados.

A Revista, criada em 1979, teve como seu primeiro editor Cláudio Laks Eizirik, que gentilmente concedeu uma esclarecedora entrevista ao conselho editorial, publicada nesta edição. Cláudio, juntamente com a dedicação dos colegas que constituíram o conselho editorial à época, lançaram a Revista procurando estabelecer uma linha editorial 
embasada na psiquiatria dinâmica e na clínica, abordando os temas de interesse dos psiquiatras da época que eram debatidos em jornadas e congressos locais.

Ao longo desses anos, 12 dedicados colegas foram os editores da Revista, e 70 participaram ativamente do seu conselho editorial. Até o ano de 2003, foram publicados 79 exemplares e 943 artigos. A Revista foi crescendo a cada gestão, passando por diversas etapas importantes, como a criação e reformulação dos conselhos editorial, consultivo nacional e internacional, a avaliação dos artigos por pares, a atualização das normas de redação e a conseqüente inclusão da Revista nos mais relevantes indexadores internacionais.

Hoje a Revista de Psiquiatria do Rio Grande do Sul faz parte do patrimônio científico nacional graças ao efetivo envolvimento e à participação desses colegas psiquiatras, dos autores dos artigos e dos leitores que contribuíram para seu crescimento, respeitabilidade, maturidade e qualificação científica. Conquistamos, neste ano, uma base financeira sólida para a Revista, através da inclusão de publicidade nas edições, trabalho este que foi iniciado na gestão anterior. Esta seqüência de realizações só foi possível graças ao trabalho integrado dos colegas psiquiatras que nos antecederam, pensando sempre no futuro da Revista, e ao incansável apoio das diretorias da SPRS, que sempre apostaram na Revista e hoje são representadas pelo Presidente Alfredo Cataldo Neto e seus colegas de diretoria.

Em função disso, festejamos o aniversário da Revista, brindado com uma qualificada programação científica e social. Em 11 de setembro, tivemos com uma mesa-redonda com a presença de convidados de grande expressão do nosso meio, como Cláudio Laks Eizirik, Ivan Antonio Izquierdo e Maria Lúcia Tiellet Nunes, que abordaram o tema "Produção do conhecimento e publicações em psiquiatria". Nesta mesma data ocorreu o jantar e o baile com homenagens aos 12 ex-editores pelos serviços prestados e aos cinco autores que mais publicaram na Revista nesses 25 anos: Maria Lucrécia Scherer Zavaschi, Cláudio Maria da Silva Osório, Sidnei Samuel Schestatsky, Cláudio Laks Eizirik, Paulo Silva Belmonte de Abreu.

Para comemorar os 25 anos da Revista, introduzimos mais algumas mudanças e inovações sugeridas por diversos colegas, que acreditamos irão contribuir para tornar a Revista realidade atual do conhecimento científico. Assim, modernizamos a metodologia de editoração e de revisão, continuaremos a editorar a Revista na língua portuguesa, publicando-a em papel, e iniciamos a editoração eletrônica integral dos textos na língua inglesa, através do ingresso no SciELO, uma de nossas mais recentes conquistas, juntamente com a inclusão no Portal de Periódicos QUALIS Nacionais da Capes, sendo classificada em nível A e passando a contar com o apoio do CNPq, uma das instituições científicas mais respeitadas em nível nacional. Com isso, os artigos publicados em nossa Revista também poderão ser lidos mais facilmente e rapidamente no exterior, através do site www.scielo.br/rprs. Nesta edição, comemorativa aos 25 anos, publicamos uma capa com a foto do pôr-do-sol no Guaíba, um de nossos cartões postais mais bonitos (foto produzida por Fotografia Litus). O leitor encontrará nesta edição um editorial a convite, de autoria do historiador Edson Cheuiche, que traça um interessante histórico em homenagem aos 120 anos do Hospital Psiquiátrico São Pedro, instituição considerada o berço da psiquiatria gaúcha, onde inúmeros profissionais iniciaram sua formação.

Estamos levando ao conhecimento de nossos leitores artigos das mais diversas procedências, como que a comprovar o acerto deste momento, em que celebramos 25 anos de publicação ininterrupta.

Para abrir a seção de artigos, contamos com um trabalho especial do renomado psiquiatra inglês Timothy Crow. Conhecido no meio acadêmico, este autor nos brinda com um artigo que resume sua originalíssima teoria sobre assimetria cerebral na etiologia da esquizofrenia, sugerindo que este transtorno seria o preço que a humanidade pagou pela aquisição da linguagem.

Publicamos quatro artigos originais. $O$ primeiro, de Martins et al., é um artigo bastante instigante que discute, à luz da figura de John Nash, as enormes dificuldades encontradas, em vários casos de transtornos esquizofrênicos, para se diferenciar sintomas de humor e psicose. Para isso, os autores brindam os leitores com um novo instrumento em nosso meio, publicado na íntegra nesta edição: o Inventário de Critérios Operacionais para Doenças Psicóticas (OPCRIT). Seguem-se dois artigos originais acerca de um tema cada vez mais estudado na psiquiatria contemporânea: o transtorno de estresse pós-traumático (TEPT). No primeiro caso, Stein et al. publicam o primeiro artigo em nosso meio com dados de 
uma amostra em uma unidade de saúde de atenção primária, trazendo resultados alarmantes sobre a alta prevalência deste transtorno em populações pobres em uma cidade brasileira e a alta comorbidade com sintomas depressivos e alcoolismo. O segundo artigo sobre TEPT, de Berger et al., apresenta aos leitores uma escala para rastreamento do TEPT e a metodologia cuidadosa exigida pelo método de equivalência semântica quando da sua versão para a língua portuguesa. O quarto artigo original é de Carvalho et al., que fazem inicialmente uma revisão crítica da literatura e após propõem, de forma bastante criativa e prática, algoritmos para o tratamento farmacológico do transtorno de personalidade limítrofe. Esses colegas vêm preencher um grande hiato em nossa literatura sobre este tema, e a proposta desses algoritmos auxiliará sobremaneira a todos os que se dedicam a atender pacientes tão graves.

Apresentamos uma comunicação breve de Ribeiro et al. Este artigo apresenta dados preliminares de uma amostra de 1.062 voluntários do processo de normatização de valores para o International Affective Picture System, utilizado na investigação experimental.

No seguimento, apresentamos dois trabalhos de revisão. O primeiro é do colega canadense Edward Shorter, que nos traz importantes reflexões sobre o descaso com a história da psicofarmacologia. Esse descaso, segundo o autor, acaba por acarretar a rejeição de drogas que poderiam ser utilizadas nos dias atuais, mas que foram rejeitadas de forma enganosa. O segundo, de Rosenthal et al., versa sobre os principais achados neuropsicológicos na depressão. Este artigo traz interessantes dados da literatura que podem auxiliar muito, na clínica psiquiátrica cotidiana, quem lida com pacientes deprimidos.

Temos ainda a satisfação de apresentar uma carta aos editores de um colega norteamericano sobre a sugestão, a partir de um caso clínico, do uso de naltrexona em altas doses para tratar auto-agressividade em crianças. O intercâmbio de nossa Revista com colegas não-brasileiros sugere que estamos ampliando os horizontes de publicação para além de nosso país. Também apresentamos outra carta aos editores bastante interessante do colega Antônio Teixeira sobre o artigo "PANDAS e a hipótese imunológica no transtorno obsessivo-compulsivo", de Ronchetti et al., publicado em nosso número anterior. Publicamos também a réplica dos autores aos comentários do colega mineiro, o que nos gratifica muito, pois este espírito de debate científico é o que se espera de uma revista que se propõe plural.

Em uma das resenhas, Nazur Vasconcellos comenta o Manual de técnica psicanalítica, de David Zimerman; em outra, Eugenio Grevet aborda o livro Terapia cognitivocomportamental na prática clínica, de Paulo Knapp et al. Muito nos honra publicar essas resenhas sobre dois livros coordenados por colegas gaúchos em áreas tão fundamentais na prática psiquiátrica contemporânea e que, com certeza, em muito contribuirão para a psiquiatria brasileira.

Como mencionado anteriormente, apresentamos uma entrevista com Cláudio Laks Eizirik, responsável pelos primeiros passos de nossa Revista há já longínquos 25 anos. Eizirik, além de suas já reconhecidas qualidades como psiquiatra, psicanalista e professor, traz aos leitores uma visão histórica daqueles tempos e discute aspectos cruciais nos dias atuais para os meios de publicação científica. A entrevista com o Cláudio revela que, se chegamos a uma edição comemorativa de alto nível como esta, é porque, nesses últimos 25 anos, os colegas editores e os dos conselhos editorial e consultivo trabalharam muito e muito bem, assim como foi fundamental a contribuição de todos os colegas que vêm acreditando na Revista de Psiquiatria do Rio Grande do Sul através do envio de seus trabalhos para publicação. Este número é dedicado, portanto, a todos: companheiros de trabalho, autores e leitores.

Boa leitura a todos.

Flávio Shansis e Jacó Zaslavsky

Copyright (C) Revista de Psiquiatria do Rio Grande do Sul - SPRS 